\title{
Role of ICT on Marketing Agricultural Crops (Date) from View Point of Agriculture Experts (Case Study of Khuzestan Province)
}

\author{
Mohamad Kamal Ebrahimi Filouri \\ M.S Student in Agriculture Management, Department of Agriculture, ,Islamshahr Branch \\ Islamic Azad University, Tehran, Iran, m.kamalebrahimi@gmail.com
}

*Azita Zand

Assistant Professor of Agricultural Extension \& Education, department of Agriculture, ,Islamshahr Branch Islamic Azad University, Tehran, Iran; azitazand@iiau.ac.ir

Mohammad Mohammadi

Assistant Professor of Agricultural Extension \& Education,Department of Agriculture, ,Islamshahr Branch Islamic Azad University, Tehran, Iran; mohammadimm@yahoo.com

Doi:10.5901/mjss.2015.v6n5s1p98

\begin{abstract}
This research examines the effective role of ICT on marketing agricultural crops. This is applied research and the methodology is descriptive-correlation. Statistical society of this research is all agriculture experts being experienced in the field of marketing date at Khuzestan province. Results of correlation between individual and occupational properties of experts by supplying and selling date shows that there is positive significant relationship between organizational position, education, service record, date culturing, date business and satisfaction of budget allocated to ICT sector for selling date. Results of correlation between individual and occupational properties of influential experts in date market shows that there is positive significant relationship between organizational position, email, weblog, date culturing, date business and satisfaction of budget allocated to ICT sector for selling date. Results of correlation between individual and occupational properties of experts with reducing cost of producing and selling date shows that there is positive significant relationship between age, organizational position, field of study, service record, email, weblog, date culturing and date business with reducing cost of producing and selling date. Results of multi variable regression show that the variables including: service record, organizational position, education and being informed of support rules, nearly describes $34 \%$ changes of dependant variable.
\end{abstract}

Keywords: Role, ICT, Date Marketing, Khuzestan Province

\section{Introduction}

In Khuzestan province nearly $75 \%$ of date is sold by traditional marketing method and it is less applied from modern technologies. It seems that by using modern technologies and Internet based marketing, it is possible to improve the rate of selling date. Most of farmers are not fully informed of modern marketing methods and technologies (Talaei and Khosravipour 2009). In case of correct application of modern technologies by the farmers and agriculture experts also benefit from such technology, this issue may be very effective on development of agriculture; nevertheless, due to terms \& conditions of small scale farmers and increasing social class distinction between wealthy and poor farmers and more application of such technology by the large wealthy farmers, it is expected at ICT may be available for the entire classes of society and leading to reducing poverty at entire level (Gol Mohammadi and et al 2006). In Khuzestan province due to absence of enough infrastructures, being far away villages, lack of familiarity of farmers and gardeners with palm tree management and modern communication technologies for agricultural planners, such technology does not play key role on increasing culturing and selling date. The agriculture cooperatives prefer to hold face-to-face classes instead of printing brochure (Fami and et al 2012). The importance of correct application of ICT on marketing agricultural crops, play key role on improvement of this technology. Agricultural managers having positive, self-motivated attitude for application of new technology play crucial role on promotion and widespread of ICT application ( khajeh Shahkouhi 2013). Due to any reason in past and in compliance with basic structure of agricultural sector, the marketing of agricultural crops was neglected. On the other hand, in most of countries of world famers attempt to benefit from new technologies and strategies for increasing quality of the products and cope with new scientific problems (Jalali 2012). Benefiting new 
technologies including: Internet has created great evolution on marketing methods and selling agricultural products. Using Internet websites and offering required information to the customers, has increased satisfaction and trustworthiness of the buyers of agricultural crops (Range \& Etzkowit 2010). Another research deals with studying marketing and export of Shahani date (case study of Fars province, Jahrom city). creation of new attitude toward process of innovation and marketing is the best way to reach enhancement quality product(Plant \& Odame 2008). In this research, in generalities about date, marketing service, marginal amounts of marketing and profit of marketing factors is studied. Therefore, improving the marketing system depends on paying more attention on transportation service, processing, warehousing and electing correct method of packaging date. In addition, through investment on additional products of Shahani date, it is possible to prevent from wastes of date at industrial application (Shajari and et al 2002). Establishment of innovation and marketing products at organizational environment depends on specific conditions including: understanding the requirements of users, regarding product market, developing technology effectively, application of modern methods, benefiting scientific tools and having a manager being responsible against improvement of such technologies (Kaplan \& Palmer 2007).

General Objective: Role of ICT technology on marketing agricultural crops (date) from view point of agriculture experts (cases study of Khuzestan)

\section{Specific Objectives}

1) Studying individual properties of agricultural experts of Khuzestan province.

2) There is significant relationship between individual and occupational properties of agriculture experts with electronic readiness.

3) There is significant relationship between individual and occupational properties of agriculture experts with influence of ICT.

4) There is significant relationship between individual and occupational properties of agriculture experts with electronic marketing.

5) There is significant relationship between individual and occupational properties of agriculture experts with supplying and selling date.

6) There is significant relationship between individual and occupational properties of agriculture experts with influence at date market.

7) There is significant relationship between individual and occupational properties of agriculture experts with reducing cost of selling date

\section{Materials and Methods}

This is applied research and its methodology is descriptive-correlation. Statistical society of this research is 144 agriculture experts of Khuzestan province being experienced in the field of palm tree and marketing. The sampling method was census. In this research, in order to collect information, it was benefit from questionnaire designed by the researcher. This questionnaire has 3 sections. At first section the demographic information for experts of agriculture organization of Khuzestan province. The second section consists of questions in relation to electronic readiness of experts of the agriculture organization and the third section consists of questions about role of ICT on date market. Aforesaid questionnaire upon being revised was submitted to the scholars, professors and experts in the field of marketing and agriculture to confirm the validity of its questionnaires. Results of Alpha Cronbach for the questionnaire of ICT was 0.85 . In order to determine the reliability of questionnaire, 30 experts completed the questionnaire on empirical basis and the following data was obtained:

\begin{tabular}{|l|c|c|}
\hline Different sections of questionnaire & Number of forms & Alpha Cronbach \\
\hline Readiness at ICT sector & 24 & 0.85 \\
\hline ICT & 11 & 0.87 \\
\hline Marketing & 12 & 0.81 \\
\hline Supplying and selling & 6 & 0.80 \\
\hline Influence on market & 6 & 0.76 \\
\hline Reducing cost & 6 & 0.84 \\
\hline Competitive advantage & 9 & 0.76 \\
\hline
\end{tabular}


In order to describe research variables, it was benefit from frequency distribution, frequency percentage, cumulative frequency, average, standard deviation, coefficient of changes, maximum, minimum, correlation and step by step regression

\section{Results}

\subsection{Personal Properties of Agriculture Experts}

Among respondents there were 50 female (35.4\%) and 89 male (64.6\%). Results of studying frequency for age of respondents showed that the highest frequency of age was related to the age of 31-40 years old with frequency of $47.4 \%$ and the minimum frequency of age was related to age of 51 years and over with frequency of $13 \%$. With respect to record of culturing date, 114 respondents (82\%) have previous record of date culturing and 25 persons (18\%) did not have previous record of date culturing. With respect to attending at electronic readiness education and computer classes, 117 respondents (84\%) attended in such classes and 22 persons (16\%) did not attend at such classes. With respect to satisfaction of respondents of allocated budget for improvement of ICT in organization, 28 persons (20.1\%) have very low level of satisfaction, 56 persons (40.3\%) have low level of satisfaction, 50 persons (36\%) have medium satisfaction and 5 persons (3.6\%) have high satisfaction.

\subsection{Relationship between electronic readiness and role of ICT on research variables}

Results of correlation between individual and job properties of experts with level of electronic readiness showed that there is positive significant relationship between organizational position ( $r=0.286)$, satisfaction of allocated budget to ICT sector $(r=0.481)$ having email $(r=0.186)$ having weblog $(r=0.263)$ and negative significant relationship with field of study $(r=$ 0.221 ) with electronic readiness (table 1-2).

Table 1-2: Variables, index of variables, correlation coefficient and sig level with electronic readiness

\begin{tabular}{|l|c|c|c|c|c|l|}
\hline Sig level & Correlation coefficient & \multicolumn{2}{|c|}{ Test } & Index variable & & Anticipating variable \\
\hline & & & Index & & Index & \\
\hline 0.241 & 0.112 & Spearman & Distance & Electronic readiness & Nominal & Sex \\
\hline 0.071 & -0.154 & Spearman & Distance & Electronic readiness & Distance & Age \\
\hline 0.001 & $0.286^{* *}$ & Spearman & Distance & Electronic readiness & Sequence & Organizational position \\
\hline 0.323 & 0.084 & Spearman & Distance & Electronic readiness & Sequence & Education \\
\hline 0.009 & $-0.221^{* *}$ & Spearman & Distance & Electronic readiness & Nominal & Field of study \\
\hline 0.536 & 0.053 & Spearman & Distance & Electronic readiness & Distance & Service record \\
\hline 0.582 & -0.047 & Spearman & Distance & Electronic readiness & Nominal & Computer education \\
\hline 0.028 & $0.186^{*}$ & Spearman & Distance & Electronic readiness & Nominal & Email \\
\hline 0.002 & $0.263^{* *}$ & Spearman & Distance & Electronic readiness & Nominal & Having weblog \\
\hline 0.603 & 0.044 & Spearman & Distance & Electronic readiness & Nominal & Date culturing \\
\hline 0.555 & 0.05 & Spearman & Distance & Electronic readiness & Nominal & Date business \\
\hline 0.053 & 0.165 & Spearman & Distance & Electronic readiness & Sequence & Introduction to the rules \\
\hline 0.000 & $0.481^{* *}$ & Spearman & Distance & Electronic readiness & Sequence & Satisfaction of budget allocated to ICT \\
\hline
\end{tabular}

Sig level: $5 \%$ sig level: $1 \%$

\subsection{Correlation of ICT with some research variables}

Results of correlation between individual and job properties of experts with influence of ICT showed that there is positive relationship between organizational position $(r=0.241)$ field of study $(r=0.197)$ satisfaction of budget allocated to ICT $(r=0.221)$ having email $(r=0.241)$ having weblog $(r=0.209)$ date culturing $(r=0.254)$ date business $(r 0.250)$ with influence on ICT technology 
Table 1-3: Variables, index of variables, correlation coefficient and sig level with electronic readiness

\begin{tabular}{|c|c|c|c|c|c|l|}
\hline Sig level & Correlation coefficient & \multicolumn{2}{|c|}{ Test } & Index criterion & & Anticipating variable \\
\hline & & & Index & & Index & \\
\hline 0.658 & -0.038 & Spearman & Distance & ICT & Nominal & Sex \\
\hline 0.089 & -0.145 & Pearson & Distance & ICT & Distance & Age \\
\hline 0.004 & $0.241^{\star *}$ & Spearman & Distance & ICT & Sequence & Organizational position \\
\hline 0.929 & 0.008 & Spearman & Distance & ICT & Sequence & Education \\
\hline 0.02 & $0.197^{*}$ & Spearman & Distance & ICT & Nominal & Field of study \\
\hline 0.969 & -0.003 & Pearson & Distance & ICT & Distance & Service record \\
\hline 0.406 & -0.071 & Spearman & Distance & ICT & Nominal & Computer education \\
\hline 0.006 & $0.241^{* *}$ & Spearman & Distance & ICT & Nominal & Email \\
\hline 0.014 & $0.209^{*}$ & Spearman & Distance & ICT & Nominal & Having weblog \\
\hline 0.003 & $0.254^{\star \star}$ & Spearman & Distance & ICT & Nominal & Date culturing \\
\hline 0.003 & $0.250^{* \star}$ & Spearman & Distance & ICT & Nominal & Date business \\
\hline 0.589 & -0.046 & Spearman & Distance & ICT & Sequence & Introduction to the rules \\
\hline 0.009 & $0.221^{* *}$ & Spearman & Distance & ICT & Sequence & Satisfaction of budget allocated to ICT \\
\hline
\end{tabular}

\subsection{Correlation of electronic marketing with some research variables}

Results of correlation between individual and job properties of experts with influence of electronic marketing showed that there is positive relationship between organizational position ( $r=0.305)$ education $(r=0.200)$ service record $(r=0.425)$ having email $(r=0.210)$ having weblog $(r=0.302)$ date culturing $(r=0.268)$ date business $(r=0.242)$ with influence on electronic marketing

Table 1-4: Variables, index of variables, correlation coefficient and sig level with electronic marketing

\begin{tabular}{|c|c|c|c|c|c|l|}
\hline Sig level & Correlation coefficient & \multicolumn{2}{|c|}{ Test } & Index criterion & & Anticipating variable \\
\hline & & & Index & & Index & \\
\hline 0.535 & -0.053 & Spearman & Distance & Marketing & Nominal & Sex \\
\hline 0.214 & 0.106 & Pearson & Distance & Marketing & Distance & Age \\
\hline 0.000 & $0.305^{\star *}$ & Spearman & Distance & Marketing & Sequence & Organizational position \\
\hline 0.018 & $0.200^{*}$ & Spearman & Distance & Marketing & Sequence & Education \\
\hline 0.183 & 0.114 & Pearson & Distance & Marketing & Nominal & Field of study \\
\hline 0.000 & $0.425^{\star *}$ & Pearson & Distance & Marketing & Distance & Service record \\
\hline 0.842 & -0.017 & Spearman & Distance & Marketing & Nominal & Computer education \\
\hline 0.013 & $0.210^{\star}$ & Spearman & Distance & Marketing & Nominal & Email \\
\hline 0.000 & $0.302^{* *}$ & Spearman & Distance & Marketing & Nominal & Having weblog \\
\hline 0.001 & $0.268^{\star *}$ & Spearman & Distance & Marketing & Nominal & Date culturing \\
\hline 0.001 & $0.242^{* *}$ & Spearman & Distance & Marketing & Nominal & Date business \\
\hline 0.675 & 0.036 & Spearman & Distance & Marketing & Sequence & Introduction to the rules \\
\hline 0.789 & -0.023 & Spearman & Distance & Marketing & Sequence & Satisfaction of budget allocated to ICT \\
\hline
\end{tabular}

Sig level: $5 \%$ Sig level: $1 \%$

\subsection{Correlation of supplying and selling date with some research variables}

Results of correlation between individual and job properties of experts with supplying and selling date showed that there is positive relationship between organizational position $(r=0.321)$ education $(r=0.277)$ service record $(r=0.275)$ date culturing ( $r=0.298)$ date business ( $r=0.234)$ satisfaction of allocated budget to ICT ( $r=0.194)$ with influence on electronic marketing 
Table 1-5: Variables, index of variables, correlation coefficient and sig level with supplying and selling date.

\begin{tabular}{|l|c|c|c|c|c|l|}
\hline Sig level & Correlation coefficient & \multicolumn{2}{|c|}{ Test } & Index criterion & & Anticipating variable \\
\hline & & & Index & & Index & \\
\hline 0.298 & -0.089 & Spearman & Distance & Supplying and selling & Nominal & Sex \\
\hline 0.281 & 0.092 & Pearson & Distance & Supplying and selling & Distance & Age \\
\hline 0.000 & $0.321^{* *}$ & Spearman & Distance & Supplying and selling & Sequence & Organizational position \\
\hline 0.464 & -0.024 & Spearman & Distance & Supplying and selling & Sequence & Education \\
\hline 0.001 & $0.277^{\star *}$ & Pearson & Distance & Supplying and selling & Nominal & Field of study \\
\hline 0.002 & $0.257^{\star *}$ & Pearson & Distance & Supplying and selling & Distance & Service record \\
\hline 0.409 & -0.071 & Spearman & Distance & Supplying and selling & Nominal & Computer education \\
\hline 0.317 & 0.086 & Spearman & Distance & Supplying and selling & Nominal & Email \\
\hline 0.243 & 0.132 & Spearman & Distance & Supplying and selling & Nominal & Having weblog \\
\hline 0.000 & $0.298^{* *}$ & Spearman & Distance & Supplying and selling & Nominal & Date culturing \\
\hline 0.000 & $0.234^{* *}$ & Spearman & Distance & Supplying and selling & Nominal & Date business \\
\hline 0.068 & 0.155 & Spearman & Distance & Supplying and selling & Sequence & Introduction to the rules \\
\hline 0.022 & $0.194^{*}$ & Spearman & Distance & Supplying and selling & Sequence & Satisfaction of budget allocated to ICT \\
\hline
\end{tabular}

\subsection{Correlation of influence on date market with some research variables}

Results of correlation between individual and job properties of experts with supplying and selling date showed that there is positive relationship between organizational position ( $r=0.424)$ having email $(r=0.200)$ having weblog $(r=0.360)$ date culturing ( $r=0.235)$ date business ( $r=0.311)$ and satisfaction of budget allocated to ICT $(r=0.174)$ and influence on date market

Table 1-6: Variables, index of variables, correlation coefficient and sig level with influence on date market

\begin{tabular}{|c|c|c|c|c|c|c|}
\hline Sig level & Correlation coefficient & \multicolumn{2}{|c|}{ Test } & Index criterion & & Anticipating variable \\
\hline & & & Index & & Index & \\
\hline 0.815 & 0.02 & Spearman & Distance & Supplying and selling & Nominal & Sex \\
\hline 0.84 & -0.017 & Pearson & Distance & Supplying and selling & Distance & Age \\
\hline 0.000 & $0.424^{\star *}$ & Spearman & Distance & Supplying and selling & Sequence & Organizational position \\
\hline 0.525 & 0.054 & Spearman & Distance & Supplying and selling & Sequence & Education \\
\hline 0.245 & 0.099 & Pearson & Distance & Supplying and selling & Nominal & \begin{tabular}{|l|} 
Field of study \\
\end{tabular} \\
\hline 0.123 & 0.131 & Pearson & Distance & Supplying and selling & Distance & Service record \\
\hline 0.566 & 0.049 & Spearman & Distance & Supplying and selling & Nominal & Computer education \\
\hline 0.019 & $0.200^{*}$ & Spearman & Distance & Supplying and selling & Nominal & Email \\
\hline 0.000 & $0.360^{* \star}$ & Spearman & Distance & Supplying and selling & Nominal & Having weblog \\
\hline 0.005 & $0.235^{\star \star}$ & Spearman & Distance & Supplying and selling & Nominal & Date culturing \\
\hline 0.005 & $0.311^{* *}$ & Spearman & Distance & Supplying and selling & Nominal & Date business \\
\hline 0.181 & 0.114 & Spearman & Distance & Supplying and selling & Sequence & Introduction to the rules \\
\hline 0.041 & $0.174^{\star}$ & Spearman & Distance & Supplying and selling & Sequence & Satisfaction of budget allocated to ICT \\
\hline
\end{tabular}

\subsection{Correlation of reducing cost of production and sale with some research variables}

Results of correlation between individual and job properties of experts with reducing cost of production and sale showed that there is positive relationship between age of respondents $(r=0.261)$ organizational position $(r=0.468)$ service record $(r=0.425)$ having email $(r=0.195)$ having weblog $(r=0.345)$ date culturing $(r=0.217)$ date business $(r=0.183)$ and reducing cost of production and sale. 
Table 1-7: Variables, index of variables, correlation coefficient and sig level with reducing cost of production and sale

\begin{tabular}{|c|c|c|c|c|c|l|}
\hline Sig level & Correlation coefficient & \multicolumn{2}{|c|}{ Test } & Index criterion & & Anticipating variable \\
\hline & & & Index & & Index & \\
\hline 0.324 & 0.084 & Spearman & Distance & Supplying and selling & Nominal & Sex \\
\hline 0.002 & $0.261^{\star *}$ & Pearson & Distance & Supplying and selling & Distance & Age \\
\hline 0.000 & $0.468^{\star *}$ & Spearman & Distance & Supplying and selling & Sequence & Organizational position \\
\hline 0.389 & -0.074 & Spearman & Distance & Supplying and selling & Sequence & Education \\
\hline 0.000 & $0.300^{\star *}$ & Pearson & Distance & Supplying and selling & Nominal & Field of study \\
\hline 0.000 & $0.338^{\star \star}$ & Pearson & Distance & Supplying and selling & Distance & Service record \\
\hline 0.794 & -0.022 & Spearman & Distance & Supplying and selling & Nominal & Computer education \\
\hline 0.022 & $0.195^{\star}$ & Spearman & Distance & Supplying and selling & Nominal & Email \\
\hline 0.000 & $0.345^{\star *}$ & Spearman & Distance & Supplying and selling & Nominal & Having weblog \\
\hline 0.01 & $0.217^{\star}$ & Spearman & Distance & Supplying and selling & Nominal & Date culturing \\
\hline 0.01 & $0.183^{\star}$ & Spearman & Distance & Supplying and selling & Nominal & Date business \\
\hline 0.371 & 0.076 & Spearman & Distance & Supplying and selling & Sequence & Introduction to the rules \\
\hline 0.723 & 0.03 & Spearman & Distance & Supplying and selling & Sequence & Satisfaction of budget allocated to ICT \\
\hline
\end{tabular}

The first variable that is entered into this equation is experience of experts i.e. this variable has the highest influence and in this stage the coefficient for balance equation is $R^{2}=0.24$. On the other hand, level of $F$ equals to 68.78 and sig level is $\rho(=0.000)$ that is significant at less level of one thousand; therefore, through observing coefficient it is possible to announce that the variable of experience (service record) of experts describes $24 \%$ changes of dependant variable. In the next step, the variable of organizational position is entered into equation by balance coefficient of $R^{2}=0.30$ in addition level of $\mathrm{F}$ equals to 81.47 and is significant at level of $\rho(=0.000)$. Based on available findings in table 1-12, the variables of service record and organizational position describe nearly $30 \%$ of changes. In the third step, the variable of education is entered into regression equation by balance coefficient of $R 2=0.32$ in addition level of $F$ equals to 34.97 that is less level of one thousand $\rho(=0.000)$, by observing this coefficient it is stated that nearly $32 \%$ changes of dependant variable is described by following variables: Service record, organizational position and education. Finally, the variable of level of being familiar with support rules is entered into multi variable regression and balance coefficient equals to $R^{2}=0.34$ and level of $\mathrm{F}$ equals to $28.25 \mathrm{sig}$ level is $\rho(=0.000)$. It is stated that nearly $34 \%$ changes of dependant variable is described by variable of being familiar with support rules.

Table 1-8: Summary of different stages of independent variables on attitude of experts and influence of ICT on date marketing

\begin{tabular}{|c|c|c|l|l|}
\hline $\mathrm{F}$ & $\mathrm{R}^{2}$ & B Variables entered into equation & Variables entered into equation & Stages \\
\hline${ }^{*} 68.78$ & 0.24 & -3.23 & Service record & First step \\
\hline \multirow{2}{*}{$* 47.81$} & 0.30 & -2.67 & Service record & Second step \\
\hline \multirow{3}{*}{$* 34.97$} & 0.32 & -7.25 & Organizational position & \\
\hline & & -2.80 & Service record & Third step \\
& & -7.18 & Organizational position & \\
& & 4.44 & Education & \\
$* * 28.25$ & 0.34 & -2.87 & Service record & Fourth step \\
\end{tabular}

Sig level: $1 \%$ error

\section{Conclusion}

Results of studying age frequency of respondents showed that the highest frequency is related to the age of 31-40 years with frequency of $47.4 \%$ and $41-50$ years with frequency of $21 \%$. The lowest frequency of age is related to age of 51 years with frequency of 13 years and average age of respondents was 38.82 years. $82 \%$ of respondents had experience date culturing and $84 \%$ of respondents attended at computer training classes. In relation to the budget allocated for admission and development of ICT in organization, $20.1 \%$ of respondents announced very low satisfaction and only $3.6 \%$ were satisfied. Results of correlation between individual and job properties of experts with electronic marketing showed 
that there is positive significant relationship between organizational position, education, having email and date culturing and electronic marketing. Results of correlation between individual and job properties of experts with supplying and selling date showed that, there is positive significant relationship between organizational position, field of study, date culturing and date business and the budget allocated for development of ICT. Results of correlation between individual and job properties of experts with influence at date market showed that there is positive significant relationship between organizational position, having email and weblog, date culturing and date business and satisfaction of budget allocated for ICT section. Results of correlation between individual and job properties of experts with reducing the cost of producing and selling date showed that there is positive significant relationship between organizational position, field of study, service record, having email and weblog, date culturing and date business and satisfaction of budget allocated for ICT section. Results of multi variable regression showed that the variable of service record, organizational position, education and being familiar with support rules describe nearly $34 \%$ of changes of dependant variable. Hailu, 2009, found in their study entitled "potentials of ICT in the agricultural sector" that ICT is an important factor in economic development and growth in the country. There, it is mentioned that marketing of the produce along with ICT could bring about and efficient agriculture. Nnadi et al 2010, carried out research in order to examine the influence of ICT on increasing income share of farmers from agricultural crops in Australia. Results of research showed that farmers benefit from electronic methods for marketing their crops, were more successful in the field of selling their agricultural crops.

\section{Recommendations}

1) Applying from experts having experience in related field and higher education in the field of electronic marketing.

2) Holding educational classes for farmers to be familiar with ICT in the way of marketing date and transferring knowledge to other farmers.

3) Creation of electronic website for exchanging price of buying and selling data through experts.

4) Enacting support rules in relation to applying experts from ICT by the government.

\section{References}

Khajeh Shahkouhi Alireza 2013, Analyzing role of ICT on life quality of rural, Case study of Gharnabad and Isfahankalate village, Gorgan village, Scientific and Research Quarterly Periodical of Golestan University, Issue.7, Spring 2013

Jalali 2012, Social, economic influence for development of ICT applications at rural information databank of Iran, Website of Ministry of IT \& Communication, Research articles and plans

Gol Mohammadi and et al, ICT and its role on employment and exploitation of women, Abstract of articles at national conference on women and Internet at 3rd millennium, Research center of Niro, Nov 2006, pages, 26-27

Talei Khosravipour 2009, Necessity of ICT approach for promoting and educating agriculture, Set of abstract of articles on first regional conference of agriculture and natural resources, Islamic Azad University, Ramhormoz branch, page. 26

Ganj Ali, Hamid Piri, Eisa Ataei Najmeh 2002, Studying problems of marketing and exporting Shahani date, Case study of Fars province, National conference on date, potentials and challenges of producing and exporting date, Agricultural economics and its development, $10^{\text {th }}$ year, Issue.39, Autumn 2002

Bagheri Shaban Ali Fami Ghasemi Ghafari and Shirdel 2012, Studying attitude of experts for promoting agriculture in Ardebil province toward application of mobile on improvement of agriculture, Summary of articles at $4^{\text {th }}$ congress on promoting and educating agriculture and natural resources of Iran, Tehran, Agriculture Applied Sciences Higher Education Institute Publications

Hailu, B. (2009). "The Impact of agricultural policies on small holders innovation capacities. M. SC thesis communicational and innovation studies group. Wageningen university department of social science.

Pant, P., L. and Odame, H., H. (2008). "Asseaaing social Innovation in agriculture research and development partnership".Apaper prepared for workshop "Rethinking Impact", Cali-Colombia, March 26-27, 2008.

Ranga, M. and Etzkowit, H., J. (2010). "The Gender Dimension of Technology, Innovation and Entrepreneur". Journal of Technology Management and Innovation, vol 5(1), pp: $1-5$.

Nnadi, F.N., Chikaire, J., Ejiogu-Okereke, N. and Nwakwasi, R. N . (2010) Information and Communication Technology ( ICT) For Food Production and Distribution. Proceedings of the 44th Annual Conferences of Agriculture Society of Nigeria Held at Ladoke Akinkal University of Technology, Oyo State. 18th-22nd October. 